\title{
Relationship between pancreatic parenchyma loss and early postoperative hyperglycemia in patients with benign pancreatic diseases
}

\author{
Kan Wen ${ }^{1,2} \cdot$ Chunyuan Cen ${ }^{1,2} \cdot{\text { Leidi } \mathrm{Wu}^{1,2} \cdot \text { Mengting Huang }}^{1,2} \cdot$ Hongli Yang $^{1,2} \cdot$ Xiaofei Yue $^{1,2} \cdot$ Yu Zhang ${ }^{1,2}$. \\ Guina $\mathrm{Ma}^{1,2} \cdot$ Xin $\mathrm{Li}^{1,2} \cdot$ Ping Han ${ }^{1,2}$
}

Received: 25 December 2020 / Revised: 6 March 2021 / Accepted: 10 March 2021 / Published online: 4 April 2021

(c) The Author(s) 2021

\begin{abstract}
Objective To evaluate the relationship between pancreatic parenchyma loss and early postoperative hyperglycemia in patients with benign pancreatic diseases.

Methods A total of 171 patients with benign pancreatic tumors or chronic pancreatitis, whose preoperative fasting blood glucose (FBG) was normal and who underwent partial pancreatectomy were reviewed. The pancreatic volume was measured by CT imaging before and after the operation. According to their different pancreatic resection volume (PRV), 171 patients were divided into five groups: $<30 \%, 30 \%-39 \%, 40 \%-49 \%, 50 \%-59 \%$, and $\geq 60 \%$. The correlation between the PRV and postoperative FBG was investigated. According to the postoperative FBG value, the patients were divided into a hyperglycemia group (HG) and nonhyperglycemia group (non-HG) to explore the best cutoff value of the PRV between the two groups. Results There were significant differences in the postoperative FBG among the five groups (PRV <30\%, 30\%-39\%, 40\%$49 \%, 50 \%-59 \%$, and $\geq 60 \%$ ). The PRV was positively correlated with postoperative FBG in the benign tumor group and chronic pancreatitis group $(R=0.727$ and 0.651 , respectively). ROC curve analysis showed that the best cutoff value of the PRV between the HG $(n=84)$ and non-HG $(n=87)$ was $39.95 \%$ with an AUC $=0.898$; the sensitivity was $89.29 \%$, and the specificity was $82.76 \%$.

Conclusion There was a linear positive correlation between the postoperative FBG level and PRV. Patients with a PRV $\geq$ $40 \%$ are more likely to develop early postoperative hyperglycemia.
\end{abstract}

Keywords Diabetes mellitus $\cdot$ Pancreatic surgery $\cdot$ Remnant pancreatic volume $\cdot$ Pancreatic endocrine insufficiency $\cdot$ CT imaging

\section{Introduction}

In recent years, the number of surgeries for benign pancreatic diseases has increased rapidly [1,2]. On the one hand, the increased use of imaging modalities such as CT and MRI has led to an increase in the number of benign pancreatic tumors incidentally diagnosed [3,4]. On the other hand, due

Ping Han

cjr.hanping@vip.163.com

1 Department of Radiology, Union Hospital, Tongji Medical College, Huazhong University of Science and Technology, Wuhan 430022, China

2 Hubei Province Key Laboratory of Molecular Imaging, Wuhan 430022, China to many risk factors, including alcohol consumption, biliary stones, and inherited characteristics, there is an increasing incidence of chronic pancreatitis $[5,6]$. An increasing number of patients with chronic pancreatitis in whom medical treatments are ineffective or who present pseudocysts have undergone surgical treatment. The common surgical methods for benign pancreatic diseases are pancreaticoduodenectomy (PD), distal pancreatectomy (DP), duodenum-preserving pancreatic head resection (DPPHR), enucleation (EN), and central pancreatectomy (CP). These operations more or less resulted in the loss of pancreatic parenchyma.

The pancreas is an important endocrine organ in the human body. Loss of the pancreatic parenchyma directly leads to decreases in the numbers of multiple endocrine cells (alpha cells, beta cells, gamma cells, and PP cells) and affects the secretion of hormones such as insulin, glucagon, 
somatostatin, and pancreatic polypeptides, thus affecting the regulation of blood glucose by the pancreas [7]. Endocrine cells are distributed in the pancreas in the form of islets, which account for approximately $4.49 \%$ of the total pancreatic volume (0.94\% in head, $0.97 \%$ in neck, $1.41 \%$ in body, $1.41 \%$ in tail), and beta-cell mass accounts for $60 \%$ of the islets [8]. The mechanism of endocrine insufficiency after pancreatic surgery has not been thoroughly studied, especially with regard to the relationship between quantitative pancreatic parenchyma loss and postoperative fasting blood glucose (FBG). Several studies have discussed the compensatory capacity of residual pancreatic parenchyma. Maignan A et al., Kwon JH et al., and Singh AN et al. believe that pancreatic parenchyma loss is a risk factor for postoperative hyperglycemia [9-11].Conversely, King J et al. stated that retaining $20 \%$ to $25 \%$ of the pancreatic parenchyma can maintain pancreatic function [12], and surgical resection of portions of the pancreatic parenchyma will not affect endocrine function.

The postoperative survival time of patients with pancreatic malignant tumors is limited, and for patients with malignant tumors, the first consideration is tumor section followed by preservation of pancreas function. For patients with curable and long-lived benign pancreatic diseases, it is necessary to explore the effect of pancreatic parenchyma loss on postoperative blood glucose. Postoperative hyperglycemia may lead to long-term complications and a decline in the quality of life in these patients. In this study, our aim was to measure pancreatic volume by CT imaging and to explore the relationship between pancreatic parenchyma loss and postoperative blood glucose to provide some reference for the maintenance of pancreatic function after partial pancreatectomy.

\section{Methods}

\section{Patients}

In this study, retrospective data from patients who underwent partial pancreatectomy in our hospital from October 2016 to October 2020 were collected. The inclusion criteria were as follows: (1) resection of the pancreatic parenchyma; (2) plain and contrast-enhanced CT images before and two week after the operation; (3) available pathological results provided after the operation; (4) no use of hypoglycemic drugs or insulin; and (5) no use of hormones, antipsychotics, or antitumor drugs. The exclusion criteria were as follows: (1) poor image quality that could not be used for analysis; (2) pathological results indicative of malignant tumors; (3) functional neuroendocrine tumors; and (4) diagnosed diabetes mellitus or impaired fasting blood glucose before surgery (Fig. 1).

A total of 171 patients met the above criteria: 37 with solid pseudopapillary tumors, 35 with intraductal papillary mucinous tumors, 14 with mucinous cystadenomas, 7 with serous cystadenomas (suspected to be malignant or have related symptoms), 22 with nonfunctional neuroendocrine tumors of the pancreas, 3 with schwannomas, and 53 with chronic pancreatitis (either unresponsive to medical treatment or presenting pseudocysts).

This study was approved by the ethics committee of our institution. CT examinations were performed for preoperative diagnosis and postoperative evaluation of recovery. Blood glucose measurement is a parameter included in clinical biochemistry blood tests. This study only collected these results, did not interfere with the patient's treatment plan, and did not divulge the patients' personal information.
Fig. 1 Flow diagram of patient enrollment
689 patients who underwent pancreatectomy for benign disease from 2016.10 to 2020.10 in a single institute

171 patients were included

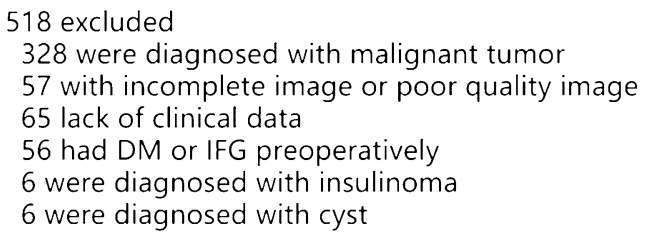




\section{Evaluation of endocrine function before and after the operation}

The blood glucose levels of the patients during the hospitalization period were statistically analyzed. The average FBG level 7 days before the operation was taken as the preoperative FBG value (results of 2 to 5 tests over 7 days), and the average FBG value 14 days after the operation was defined as the postoperative FBG value (results of 5 to 10 tests in 14 days: 1, 2 and 3 days after operation and every 2-3 days after that).

According to the postoperative FBG, the patients were divided into three groups. FBG $\geq 126 \mathrm{mg} / \mathrm{dL}(7.0 \mathrm{mmol} / \mathrm{L})$ was classified as the hyperglycemic group (HG), FBG 110 $\mathrm{mg} / \mathrm{dL}-126 \mathrm{mg} / \mathrm{dL}(6.1 \mathrm{mmol} / \mathrm{L}-7.0 \mathrm{mmol} / \mathrm{L})$ was classified as the impaired fasting blood glucose group (IFG), and FBG $<110 \mathrm{mg} / \mathrm{dL}(6.1 \mathrm{mmol} / \mathrm{L})$ was classified as the normal glycemia group (NG).

\section{Calculation of the volume loss of the pancreas}

CT was performed with a Siemens SOMATOM Definition AS+ 128 CT scanner. The voltage of the tube was 120 $\mathrm{kV}$, the tube current adopted intelligent current regulation technology, the pitch was 1.0 , the width of the collimator was $0.6 \mathrm{~mm} \times 128$, the layer thickness was $2.0 \mathrm{~mm}$, the layer spacing was $2.0 \mathrm{~mm}$, and the visual field was $390 \times 390 \mathrm{~mm}$. The enhanced scan was performed with a nonionic iodine contrast agent $(350 \mathrm{mg} \mathrm{I} / \mathrm{ml})$, which was injected into the median cubital vein with a high-pressure syringe at a flow rate of $2.5 \mathrm{ml} / \mathrm{s}$ and a total volume of $1.0 \mathrm{ml} / \mathrm{kg}$. The arterial phase, portal phase, and delayed phase were scanned 25-30 s, 55-65 s, and 150-180 s after injection, respectively.

Measurement of the pancreatic volume was performed on a Siemens syngo.via postprocessing workstation. Portal venous phase images from the enhanced CT scans were selected for measurement. At this time, the enhancement of the pancreas was obvious, the boundary was clear, and the contrast between normal pancreatic tissue and the tumor, surrounding fat, and peripheral blood vessels was clear, which could effectively avoid interference.

The outline of the pancreas of the patient was drawn layer by layer (layer thickness $=2 \mathrm{~mm}$ ) to avoid peripheral blood vessels, surrounding organs, tumors (including the cystic part and the solid part), stones (larger than $5 \mathrm{~mm}$ ), calcification (larger than $5 \mathrm{~mm}$ ), inflammatory exudation, postoperative necrosis, etc., and only the enhanced pancreatic parenchyma was outlined (Fig. 2). Through the threedimensional volume of interest (VOI) measurement tool, the preoperative and postoperative pancreatic volume (accurate to $0.01 \mathrm{~cm}^{3}$ ) was automatically calculated according to the delineated area and layer thickness. The volume of the pancreas was measured by two radiologists with 3-5 years of working experience who were blinded to the patients' clinical information, and the average value of the measured results was taken as the final result. The uniformity between the two radiologists was tested using the intraclass correlation coefficient (ICC).

The following equations were used to calculate the relevant parameters: PRV $\left(\mathrm{cm}^{3}\right)=$ preoperative pancreatic volume $\left(\mathrm{cm}^{3}\right)$ - postoperative pancreatic volume $\left(\mathrm{cm}^{3}\right)$ and $\mathrm{PRV}$ ratio $=(1$-postoperative pancreatic volume/preoperative pancreatic volume) $\times 100 \%$. According to the PRV, 171
Fig. 2 a-d A schematic diagram of the volume of the pancreas. Female, 30 y, with a solid pseudopapillary tumor pathologically, underwent distal pancreatectomy and splenectomy. a Preoperative CT image. b A locally magnified picture of a region from (a). c Postoperative $\mathrm{CT}$ image. $\mathbf{d}$ A locally magnified picture of a region from (c). The volume of the pancreas was $52.45 \mathrm{~cm}^{3}$ before the operation and $31.88 \mathrm{~cm}^{3}$ after the operation
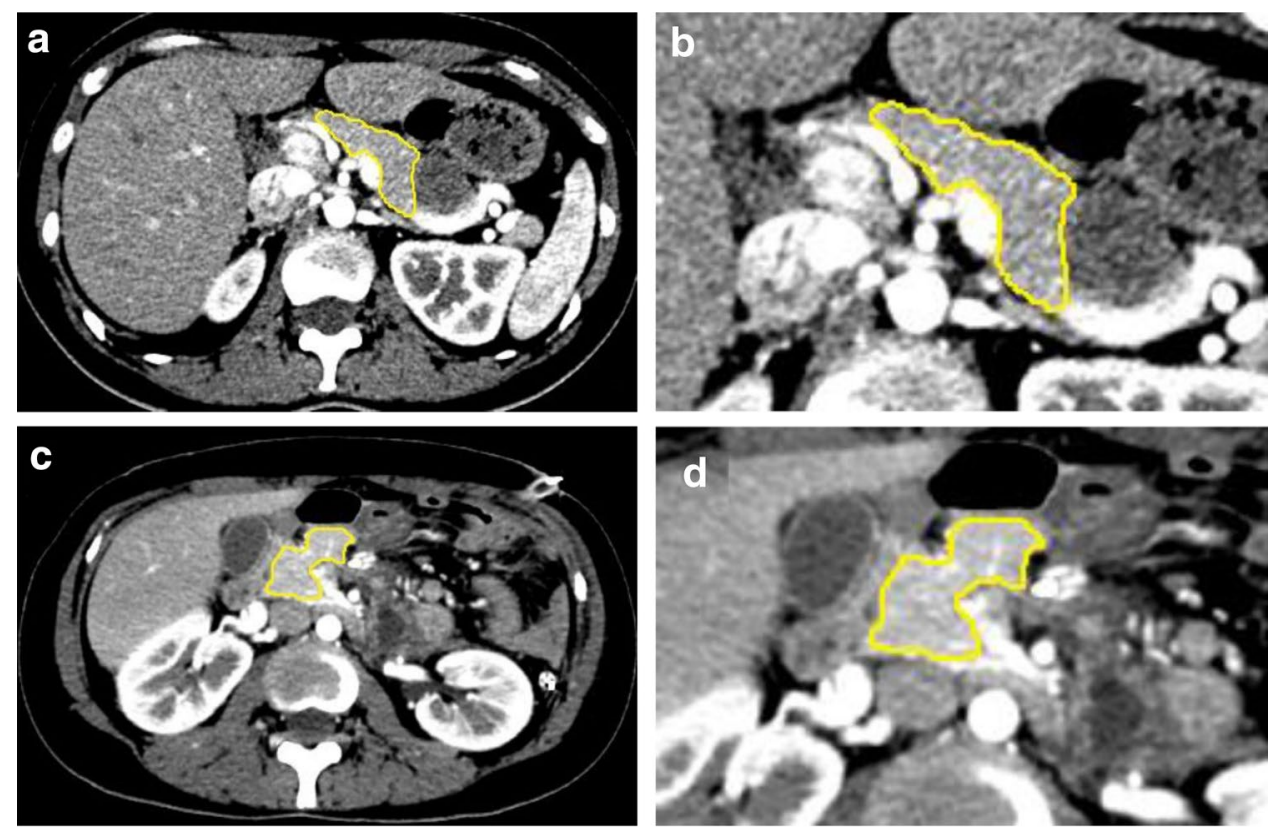
patients were divided into 5 groups based on resection volume: $<30 \%, 30 \%-39 \%, 40 \%-49 \%, 50 \%-59 \%$, and $\geq 60 \%$.

\section{Statistical analysis}

A paired-sample $t$ test was used to compare FBG before and after the operation. The preoperative and postoperative blood glucose levels of patients with benign pancreatic tumors and chronic pancreatitis were compared by independent-sample $t$ tests. The postoperative blood glucose levels of patients with different PRVs were tested by the F test. The correlation between the PRV and blood glucose level was analyzed. Receiver operating characteristic (ROC) curves were used to analyze the best cutoff value, sensitivity, and specificity of the PRV among the different postoperative blood glucose groups. The chi-square test was performed on a variety of clinical factors in the HG, IFG, and NG. $P<0.05$ was considered to be statistically significant.

\section{Results}

\section{Blood glucose level of patients before and after operation}

Among the 171 patients, 76 were male and 95 were female, with an average age of $49.1 \pm 13.3$ years. A total of 71 patients underwent DP, 61 patients underwent PD, 25 patients underwent DPPHR, 11 patients underwent EN, and 3 patients underwent $C P$.

There was no significant difference in preoperative FBG between the benign pancreatic tumor group and the chronic pancreatitis group $(P=0.162)$. However, there was a significant difference in postoperative FBG between the benign pancreatic tumor group and the chronic pancreatitis group $(P=0.010)$. The postoperative FBG in the chronic pancreatitis group was higher than that in the benign pancreatic tumor group. There was a significant difference in FBG before and after the operation $(P<0.001)$ and the blood glucose level after surgery was higher than that before surgery (Table 1).

\section{Postoperative blood glucose levels with different PRVs}

The postoperative blood glucose levels of the five groups of patients with a PRV < 30\%, 30\%-39\%, 40\%-49\%, $50 \%-59 \%$, and $\geq 60 \%$ were compared (Table 2), and there was a significant difference among the five groups. The correlation analysis between the PRV and postoperative blood glucose in the benign tumor and chronic pancreatitis groups showed that there was a positive linear correlation
Table 1 Comparison of FBG before and after operation in patients with benign pancreatic tumor and chronic pancreatitis $(\mathrm{mg} / \mathrm{dL})$

\begin{tabular}{llll}
\hline & $\begin{array}{l}\text { Preoperative } \\
\text { FBG }\end{array}$ & $\begin{array}{l}\text { Postoperative } \\
\text { FBG }\end{array}$ & P value \\
\hline $\begin{array}{l}\text { benign pancreatic tumor } \\
(n=118)\end{array}$ & $90.54 \pm 11.70$ & $128.16 \pm 23.76$ & $<0.001$ \\
$\begin{array}{c}\text { chronic pancreatitis } \\
(n=53)\end{array}$ & $93.24 \pm 12.96$ & $142.74 \pm 36.18$ & $<0.001$ \\
\begin{tabular}{l} 
P value \\
\hline
\end{tabular} & 0.162 & 0.010 & \\
\hline
\end{tabular}

Table 2 Postoperative blood glucose levels with different PRVs (mg/ dL)

\begin{tabular}{lllll}
\hline PRV & $N$ & $\begin{array}{c}\text { Benign pancreatic } \\
\text { tumor }(n=118)\end{array}$ & $\mathrm{N}$ & $\begin{array}{c}\text { Chronic pancre- } \\
\text { atitis }(n=53)\end{array}$ \\
\hline $\begin{array}{c}<30 \% \\
(\text { group A) }\end{array}$ & 28 & $110.34 \pm 17.46$ & 2 & $110.16 \pm 9.00$ \\
$\begin{array}{c}30 \%-39 \% \\
(\text { group B) }\end{array}$ & 38 & $115.74 \pm 13.14$ & 13 & $114.12 \pm 19.44$ \\
$\begin{array}{c}40 \%-49 \% \\
\quad \text { group C) }\end{array}$ & 27 & $135.54 \pm 13.32$ & 16 & $133.02 \pm 28.26$ \\
$\begin{array}{c}50 \%-59 \% \\
\quad(\text { group D) }\end{array}$ & 17 & $156.42 \pm 16.38$ & 12 & $153.72 \pm 31.50$ \\
$\geq 60 \%$ & 8 & $165.78 \pm 15.12$ & 10 & $188.82 \pm 20.52$ \\
$\quad($ group E) & & & & $<0.001$ \\
$P$ value & & $<0.001$ & & \\
\hline
\end{tabular}

Pairwise comparison: (1) Postoperative FBG in benign tumor group: there was significant difference between group $\mathrm{A}$ and groups $\mathrm{C}, \mathrm{D}$, and $\mathrm{E}$, between group $\mathrm{B}$ and groups $\mathrm{C}, \mathrm{D}$, and $\mathrm{E}$, between group $\mathrm{C}$ and groups $\mathrm{A}, \mathrm{B}, \mathrm{D}$, and $\mathrm{E}$, between group $\mathrm{D}$ and groups $\mathrm{A}, \mathrm{B}$, and $\mathrm{C}$, and between group $\mathrm{E}$ and groups $\mathrm{A}, \mathrm{B}$, and $\mathrm{C}(P<0.05)$. (2) Postoperative FBG in chronic pancreatitis group: there were significant differences between group $\mathrm{A}$ and groups $\mathrm{D}$ and $\mathrm{E}$, between group $\mathrm{B}$ and groups $\mathrm{D}$ and $\mathrm{E}$, between group $\mathrm{C}$ and groups $\mathrm{D}$ and $\mathrm{E}$, between group D and groups $\mathrm{A}, \mathrm{B}, \mathrm{C}$, and $\mathrm{E}$, and between group $\mathrm{E}$ and groups $\mathrm{A}, \mathrm{B}, \mathrm{C}$, and $\mathrm{D}(P<0.05)$

( $R=0.727$ and 0.651 , respectively; $P<0.001$ for both) (Fig. 3).

\section{Comparison among the HG, IFG and NG}

According to postoperative FBG, 171 patients were divided into three groups: HG $(n=84)$, IFG $(n=52)$ and NG $(n=35)$. As shown in Table 3, there was no significant difference in sex, age, hypertension, hyperlipidemia, BMI, or operation type among the three groups.

\section{ROC curve analysis}

In 171 patients with benign pancreatic lesions, the average PRV of the HG, IFG, and NG was $50.55 \% \pm 10.26 \%$, $34.54 \% \pm 9.35 \%$, and $30.07 \% \pm 11.79 \%$, respectively. The 

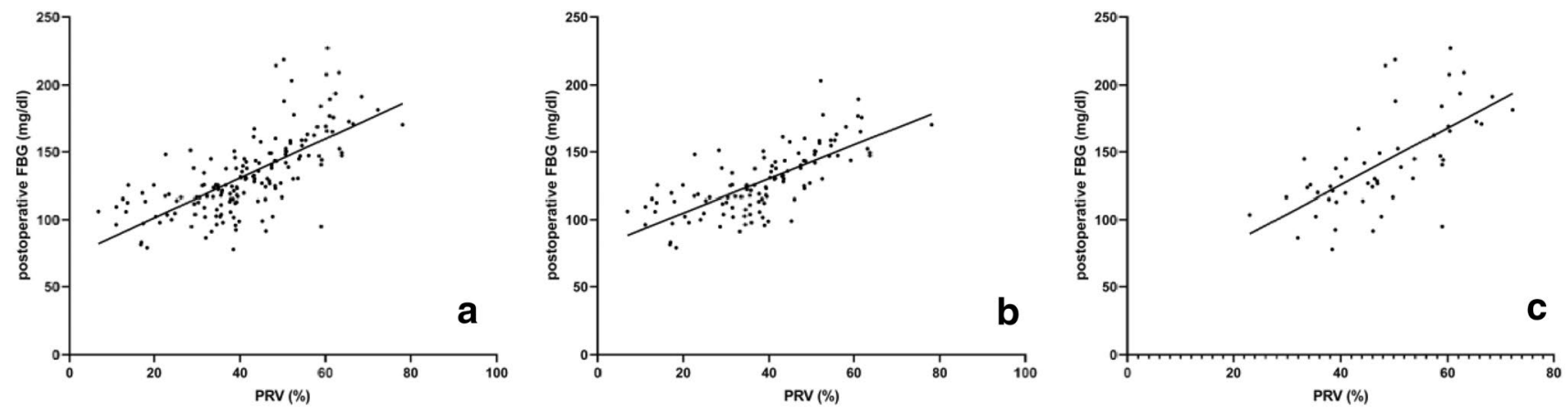

Fig. 3 a Correlation analysis between PRV and postoperative FBG in 171 patients with benign pancreatic diseases, $R=0.691, P<0.001$. b Correlation analysis between PRV and postoperative FBG in 118 patients with benign pancreatic tumor, $R=0.727, P<0.001$. c Correlation analysis between PRV and postoperative FBG in 53 patients with chronic pancreatitis, $R=0.651, P<0.001$
Table 3 Comparison of clinical factors among $\mathrm{HG}$ group, IFG group, and NG group

\begin{tabular}{llllll}
\hline & All $(n=171)$ & HG group $(n=84)$ & IFG group $(n=52)$ & NG group $(n=35)$ & $P$ value \\
\hline Sex (female) & $95 / 171$ & $52 / 84$ & $27 / 52$ & $16 / 35$ & 0.221 \\
Age & $49.1 \pm 13.3$ & $50.0 \pm 11.7$ & $49.0 \pm 13.8$ & $47.3 \pm 16.2$ & 0.605 \\
Hypertension & $38 / 171$ & $20 / 84$ & $12 / 52$ & $6 / 35$ & 0.716 \\
Hyperlipidemia & $41 / 171$ & $20 / 84$ & $13 / 52$ & $8 / 35$ & 0.973 \\
BMI $\geq 25.0 \mathrm{~kg} / \mathrm{m}^{2}$ & $29 / 171$ & $16 / 84$ & $8 / 52$ & $5 / 35$ & 0.767 \\
Operation type & & & & & 0.563 \\
PD & $61 / 171$ & $29 / 84$ & $18 / 52$ & $14 / 35$ & - \\
DP & $71 / 171$ & $35 / 84$ & $23 / 52$ & $13 / 35$ & - \\
DPPHR & $25 / 171$ & $15 / 84$ & $4 / 52$ & $6 / 35$ & - \\
EN & $11 / 171$ & $4 / 84$ & $5 / 52$ & $2 / 35$ & - \\
CP & $3 / 171$ & $1 / 84$ & $2 / 52$ & $0 / 35$ & - \\
\hline
\end{tabular}

$P D$ pancreaticoduodenectomy, $D P$ distal pancreatectomy, $D P P H R$ duodenum-preserving pancreatic head resection, $E N$ enucleation, $C P$ central pancreatectomy difference among the three groups was statistically significant $(F=65.495, P<0.001)$. The IFG and NG were combined to form the nonhyperglycemia group (non-HG). ROC curve analysis showed that the best cutoff value of the PRV between the HG and non-HG was $39.95 \%$ with an area under the curve (AUC) of $0.898(P<0.001)$; the sensitivity was $89.29 \%$, and the specificity was $82.76 \%$ (Fig. 4A).

In 118 patients with benign pancreatic lesions, the average PRV of the HG was $48.56 \% \pm 10.26 \%$, that of the IFG was $32.53 \% \pm 9.66 \%$, and that of the NG was $27.12 \% \pm$ $10.49 \%$. The difference among the three groups was statistically significant $(F=49.868, P<0.001)$. ROC curve analysis showed that the best cutoff value of the PRV between the HG and non-HG was 39.99\% with an AUC of 0.909 $(P<0.001)$; the sensitivity was $86.79 \%$, and the specificity was $90.77 \%$ (Fig. 4B).

\section{Discussion}

\section{Glycometabolic state before and after resection}

From Table 1, in patients with normal preoperative glucose metabolism, blood glucose increased to varying degrees after partial pancreatectomy, and there was a statistically significant difference before and after surgery $(P<0.001)$. When comparing the benign tumor and chronic pancreatitis groups, we found that there was a statistically significant difference in postoperative FBG with the chronic pancreatitis group presenting a higher postoperative FBG. One possible reason is that benign tumors of pancreas may have no adverse effect on the background pancreatic parenchyma, and the compensatory ability of the residual pancreatic parenchyma is strong after partial pancreatectomy, while chronic pancreatitis, as an irreversible chronic inflammatory disease of the pancreas, may also affect the function of 
Fig. 4 a ROC curve of the HG group and non-HG group in 171 patients with benign pancreatic diseases, $\mathrm{AUC}=0.898$, $P<0.001$; b ROC curve of the HG group and non-HG group in 118 patients with benign pancreatic tumor, $\mathrm{AUC}=0.909$, $P<0.001$
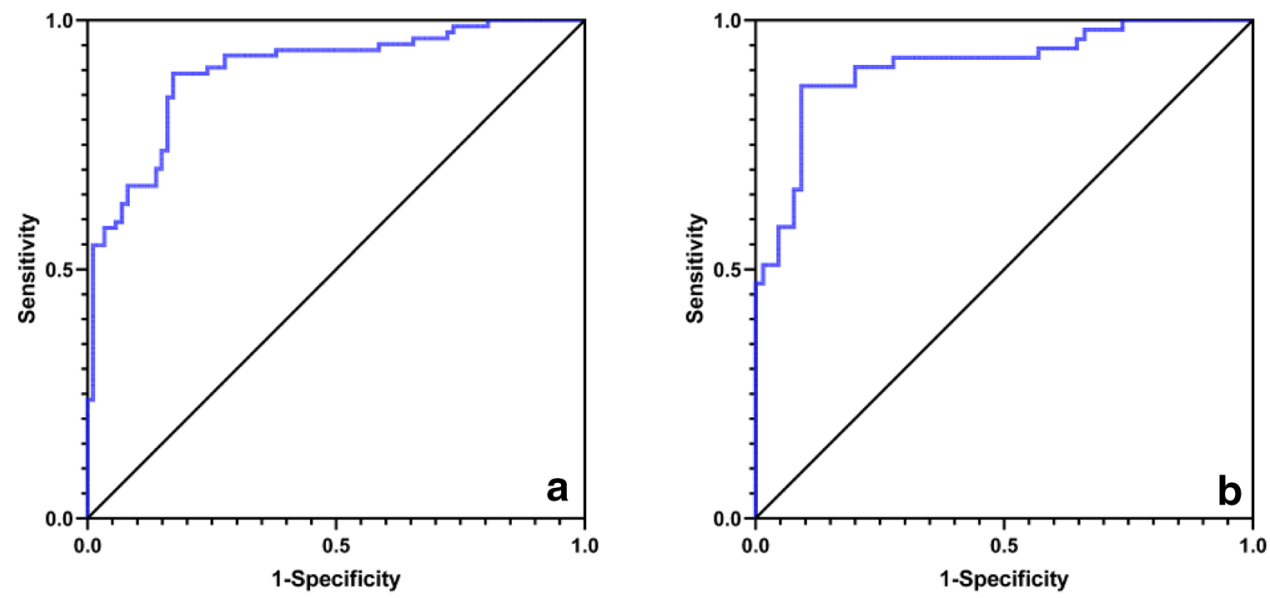

the residual pancreas, thus affecting the regulation of blood glucose after surgery $[13,14]$.

\section{The PRV and the postoperative glycometabolic state}

Due to the high variability in the locations of pancreatic tumors, the selected procedure and scope of resection also differ. The chosen operation will reduce the pancreas parenchyma while removing the lesion. Pancreatic glands are nonrenewable and pancreatic parenchyma loss directly leads to the loss of many kinds of endocrine cells and impacts the secretion of hormones, thus affecting pancreatic-mediated regulation of blood glucose [7]. Several studies have discussed the compensatory capacity of residual pancreatic parenchyma after partial pancreatectomy. King $\mathrm{J}$ et al. believe that $20 \%$ to $25 \%$ of the pancreatic parenchyma can maintain pancreatic function [12], and the pancreatic parenchyma loss due to surgical resection will not affect the endocrine function of the pancreas. Leal JN et al. compared 103 patients who underwent partial pancreatectomy with 31 patients who did not undergo surgery and concluded that the operation did not affect the probability of new-onset diabetes [15]. Shirakawa $S$ et al. concluded that a PRV $>44 \%$ was an independent risk factor for postoperative new-onset diabetes. They divided 38 patients into three groups based on PRV $(<$ $25 \%, 25 \%-50 \%$, and $>50 \%$ ) and found that the rates of newonset diabetes were $34.3 \%, 53.3 \%$, and $73.3 \%$, respectively [16]. Kwon JH et al. reported that there was a high incidence of postoperative diabetes in patients whose volume ratio of pancreatectomy was greater than 35.6\% [10]. Izumo $\mathrm{W}$ et al. showed that in the preoperative low-risk group, the cutoff value of the PRV was $42.1 \%$ [17].

In the study, we found that patients with a PRV $\geq 40 \%$ were more likely to develop early postoperative hyperglycemia $(\mathrm{AUC}=0.898, P<0.001)$, which was consistent with the cutoff value of new-onset postoperative diabetes in the abovementioned study. At the same time, we also found that there were significant differences in postoperative FBG levels in the different PRV groups $(<30 \%, 30 \%-39 \%$, $40 \%-49 \%, 50 \%-59 \%$, and $\geq 60 \%$ ), and the correlation analysis between the PRV and postoperative FBG indicated that there was a positive linear correlation.

These data show that the PRV is closely related to postoperative blood glucose in patients with benign pancreatic lesions. In recent years, several studies have compared the effectiveness of segment pancreatectomy with traditional PD or DP in the treatment of benign or low-grade malignant tumors. Segment pancreatectomy can maximize the preservation of normal pancreatic parenchyma and minimize the effect of pancreatic parenchyma loss on pancreatic endocrine function [18].

In the study by Wu et al., it was found that the incidence of diabetes was $16 \%$ after PD (95\% CI: $14 \%-17 \%), 21 \%$ after DP (95\% CI: $16 \%-25 \%)$, and 6\% after CP (95\% CI: $3 \%-9 \%$ ) [19]. Compared with other types of pancreatectomy, CP had a much lower incidence of DM. Beger HG et al. found that EN, CP, and DPPHR can better preserve pancreatic function in benign tumor surgery [20] whereas Zhou et al. reported that the incidence of pancreatic endocrine dysfunction after EN was lower than that after PD and DP [21]. The PRV has a direct effect on pancreatic endocrine function, and measuring pancreatic volume can predict the change trend of postoperative FBG.

In the pancreas of healthy adults, islets are mainly distributed in the body and tail [8]. In fact, DP may result in an approximately $70 \%$ loss of $\beta$-cell mass, while PD results in a nearly $30 \%$ loss. This is consistent with the results of $\mathrm{Wu} \mathrm{L}$ et al., who found that the incidence of diabetes after DP was higher than that after PD [19]. Postoperative hyperglycemia is a multifactorial process. $\mathrm{Wu} \mathrm{L}$ et al. considered that the risk of developing T3cDM is associated with the type of surgery, the PRV and a higher preoperative blood glucose [19]. Ko SW et al. stated that PD was a significant factor for endocrine insufficiency (HR $=3.87,95 \%$ CI: $1.12-14.66$, 
$P=0.037$ ) [22]. In our study, the effect of surgery type on early postoperative hyperglycemia was not statistically significant in 117 patients with benign pancreatic diseases. There are many reasons contributing to this, the primary of which may be the insufficient number of cases undergoing procedures with small resection volumes, such as DPPHR, $\mathrm{EN}$, and CP. This may be because the total number of cases is not large enough to show all the influencing factors. In addition, long-term follow-up of this cohort may reveal more information. In this study, patients with DM and IFG were excluded to control for preoperative confounding factors, which may be the reason why there was no difference in preoperative blood glucose among the groups.

This study is a single-center retrospective study in which the long-term blood glucose index values of the patients were not available, so it was unable to analyze longitudinal changes in glucose metabolism after the operation, which limits our interpretation of the results. At the same time, because the number of patients with chronic pancreatitis undergoing surgery is limited, they were not divided into separate groups in the analysis of postoperative blood glucose. Therefore, extending the postoperative follow-up time and further expanding the number of cases will be goals for our next study.

\section{Conclusion}

In summary, there was a positive linear correlation between the postoperative early blood glucose level and the PRV in patients with benign pancreatic lesions. Furthermore, patients with a PRV $\geq 40 \%$ were more likely to develop early postoperative hyperglycemia.

Acknowledgements We thank the Department of Pancreatic Surgery at Union Hospital of Tongji Medical College for providing help for this study. This work was financially supported by the National Natural Science Foundation of China (81873895 to P.H.).

\section{Compliance with ethical standards}

Conflict of interest The authors declare that they have no competing interests.

Ethical approval The study was approved by the ethical committee of Tongji Medical College, Huazhong University of Science and Technology. All samples were collected with informed consent in accordance with the Declaration of Helsinki.

Open Access This article is licensed under a Creative Commons Attribution 4.0 International License, which permits use, sharing, adaptation, distribution and reproduction in any medium or format, as long as you give appropriate credit to the original author(s) and the source, provide a link to the Creative Commons licence, and indicate if changes were made. The images or other third party material in this article are included in the article's Creative Commons licence, unless indicated otherwise in a credit line to the material. If material is not included in the article's Creative Commons licence and your intended use is not permitted by statutory regulation or exceeds the permitted use, you will need to obtain permission directly from the copyright holder. To view a copy of this licence, visit http://creativecommons.org/licenses/by/4.0/.

\section{References}

1. Teh SH, Diggs BS, Deveney CW, Sheppard BC (2009) Patient and hospital characteristics on the variance of perioperative outcomes for pancreatic resection in the United States: a plea for outcome-based and not volume-based referral guidelines. Arch Surg 144:713-721. https://doi.org/10.1001/archsurg.2009.67

2. Ziegler KM, Nakeeb A, Pitt HA, Schmidt CM, Bishop SN, Moreno J, Matos JM, Zyromski NJ, House MG, Madura JA, Howard TJ, Lillemoe KD (2010) Pancreatic surgery: evolution at a high-volume center. Surgery 148:702-709; discussion 709710. https://doi.org/10.1016/j.surg.2010.07.029

3. Capurso G, Vanella G, Arcidiacono PG (2018) Pancreatic cystic neoplasms in 2018: The final cut. Endosc Ultrasound 7:289292. https://doi.org/10.4103/eus.eus_48_18

4. Sun L, Wang Y, Jiang F, et al. (2019) Prevalence of pancreatic cystic lesions detected by magnetic resonance imaging in the Chinese population. J Gastroenterol Hepatol 34:1656-1662. https://doi.org/10.1111/jgh.14658

5. Wang LW, Li ZS, Li SD, et al. (2009) Prevalence and clinical features of chronic pancreatitis in China: a retrospective multicenter analysis over 10 years. Pancreas 38:248-254. https://doi. org/10.1097/MPA.0b013e31818f6ac1

6. Machicado JD, Dudekula A, Tang G, et al. (2019) Period prevalence of chronic pancreatitis diagnosis from 2001-2013 in the commercially insured population of the United States. Pancreatology 19:813-818. https://doi.org/10.1016/j.pan.2019.07.003

7. Wynne K, Devereaux B, Dornhorst A (2019) Diabetes of the exocrine pancreas. J Gastroenterol Hepatol 34:346-354. https:// doi.org/10.1111/jgh.14451

8. Ionescu-Tirgoviste C, Gagniuc PA, Gubceac E, et al. (2015) A 3D map of the islet routes throughout the healthy human pancreas. Sci Rep 5:14634. https://doi.org/10.1038/srep14634

9. Maignan A, Ouaïssi M, Turrini O, et al. (2018) Risk factors of exocrine and endocrine pancreatic insufficiency after pancreatic resection: A multi-center prospective study. J Visc Surg 155:173-181. https://doi.org/10.1016/j.jviscsurg.2017.10.007

10. Kwon JH, Kim SC, Shim IK, et al. (2015) Factors Affecting the Development of Diabetes Mellitus After Pancreatic Resection. Pancreas 44:1296-1303. https://doi.org/10.1097/MPA.00000 00000000404

11. Singh AN, Pal S, Kilambi R, et al. (2018) Diabetes after pancreaticoduodenectomy: can we predict it. J Surg Res 227:211-219. https://doi.org/10.1016/j.jss.2018.02.010

12. King J, Kazanjian K, Matsumoto J, et al. (2008) Distal pancreatectomy: incidence of postoperative diabetes. J Gastrointest Surg 12:1548-1553. https://doi.org/10.1007/s11605-008-0560-5

13. Gardner TB, Adler DG, Forsmark CE, et al. (2020) ACG Clinical Guideline: Chronic Pancreatitis. Am J Gastroenterol 115:322-339. https://doi.org/10.14309/ajg.0000000000000535

14. Zou WB, Ru N, Wu H, Hu LH, Ren X, Jin G, Wang Z, Du YQ, Cao YN, Zhang L, Chang XY, Zhang RC, Li XB, Shen Y, Li P, Li ZS, Liao Z, Chronic Pancreatitis Group of Chinese Medical Doctor Association (2019) Guidelines for the diagnosis and treatment of chronic pancreatitis in China (2018 edition). Hepatobiliary Pancreat Dis Int 18:103-109. https://doi.org/10. 1016/j.hbpd.2019.02.004 
15. Leal JN, Kingham TP, D'Angelica MI, et al. (2015) Intraductal Papillary Mucinous Neoplasms and the Risk of Diabetes Mellitus in Patients Undergoing Resection Versus Observation. J Gastrointest Surg 19:1974-1981. https://doi.org/10.1007/ s11605-015-2885-1

16. Shirakawa S, Matsumoto I, Toyama H, et al. (2012) Pancreatic volumetric assessment as a predictor of new-onset diabetes following distal pancreatectomy. J Gastrointest Surg 16:22122219. https://doi.org/10.1007/s11605-012-2039-7

17. Izumo W, Higuchi R, Yazawa T, et al. (2020) Evaluation of allowable pancreatic resection rate depending on preoperative risk factors for new-onset diabetes mellitus after distal pancreatectomy. Pancreatology. https://doi.org/10.1016/j.pan.2020.08. 005

18. Dragomir MP, Sabo AA, Petrescu G, Li Y, Dumitrascu T (2019) Central pancreatectomy: a comprehensive, up-to-date meta-analysis. Langenbecks Arch Surg 404:945-958. https://doi.org/10.1007/ s00423-019-01829-3

19. Wu L, Nahm CB, Jamieson NB, et al. (2020) Risk factors for development of diabetes mellitus (Type 3c) after partial pancreatectomy: A systematic review. Clin Endocrinol (Oxf) 92:396-406. https://doi.org/10.1111/cen.14168

20. Beger HG, Siech M, Poch B, Mayer B, Schoenberg MH (2015) Limited surgery for benign tumours of the pancreas: a systematic review. World J Surg 39:1557-1566. https://doi.org/10.1007/ s00268-015-2976-X

21. Zhou Y, Zhao M, Wu L, Ye F, Si X (2016) Short- and long-term outcomes after enucleation of pancreatic tumors: An evidencebased assessment. Pancreatology 16:1092-1098. https://doi.org/ 10.1016/j.pan.2016.07.006

22. Ko SW, Seo DW, So H, et al. (2020) Effects of pancreatic resection for benign pancreatic neoplasms on pancreatic volume and endocrine function: A long-term computed tomography-based study. Pancreatology 20:1732-1738. https://doi.org/10.1016/j. pan.2020.09.010

Publisher's Note Springer Nature remains neutral with regard to jurisdictional claims in published maps and institutional affiliations. 